\title{
Pluralidade linguística e políticas linguístico-educacionais no Brasil: rumo à gestão do multilinguismo
}

\section{Ísis Ribeiro Berger ${ }^{1}$}

Resumo: Este artigo tematiza a pluralidade linguística e as políticas linguístico-educacionais no Brasil e discute a gestão do multilinguismo na educação. O texto, cujo objetivo é estabelecer interlocuções quanto aos fatores que incidem na gestão do multilinguismo visando à promoção da pluralidade das línguas no País, parte do pressuposto de que o multilinguismo e as línguas são objeto de gestão na qual incidem relações de poder e ações de múltiplos agentes. Apresentamos, inicialmente, o quadro teórico em que se sustentam as discussões propostas: políticas linguísticas, políticas linguístico-educacionais, gestão de línguas e do multilinguismo na escola. Na sequência, discutimos sobre os desafios e potencialidades que se constituem como eixo dos debates em torno da promoção de políticas linguísticas para o multilinguismo, no Brasil. Por fim, discorremos sobre as experiências e ações que desafiam o enquadre político-linguístico monolíngue que, por longo tempo, se construiu no país e, também, encaminhamentos para a continuidade das discussões e reflexões sobre a temática aqui apresentada.

Palavras-chave: Políticas linguístico-educacionais. Gestão. Multilinguismo. Brasil.

mundo é multilíngue. Estima-se a existência de, aproximadamente, 7000 línguas no planeta, em um total de 193 países reconhecidos oficialmente pelas Organizações das Nações Unidas (ONU). Como sabemos, essas línguas não estão distribuídas nesses países em igual proporção, mas podemos afirmar, com segurança, que todos os países são multilíngues, visto que, em seus territórios, são usadas muitas línguas em suas variedades e sob os mais diversos estatutos a elas atribuídos, por meio de diferentes formas de gestão, o que implica

1 Doutora em Linguística pela UFSC, na linha de pesquisa em Política Linguística. Mestre em Letras: Linguagem e Sociedade pela Unioeste - Cascavel; Licenciada e Bacharel em Letras Português-Inglês pela Universidade Federal do Rio de Janeiro. Professora Adjunta da UNIOESTE - Campus Foz do Iguaçu. Professora do Curso de Letras (Graduação) e do Programa de Pós-Graduação Sociedade, Cultura e Fronteiras. Coordenadora do Projeto de Extensão: Multilinguismo e sociedade na tríplice fronteira. 
mundivivências das mais diversas.

A presença de muitas línguas em um mesmo território, além de contribuir enormemente para a formação cultural dos países e de representar um riquíssimo patrimônio imaterial, desvela relações de poder no contato entre seus falantes e nas formas como cada uma das línguas ou mesmo essa miríade de línguas é gerida, por meio de políticas, intervenções e ações diante delas. A pluralidade de línguas é, portanto, um tema de discussão do campo da Política Linguística.

A pesquisa acadêmica em torno das políticas linguísticas é, cada vez mais, crescente no Brasil, de modo que não faltam referências sobre as bases epistemológicas que fundamentam essa área do saber acadêmico (OLIVEIRA; ALTENHOFEN, 2011, ORLANDI, 2007, SAVEDRA; LAGARES, 2012, SILVA, 2013, entre outros). Grosso modo, podemos reiterar que a Política Linguística se constitui como campo interdisciplinar que abarca uma gama de investigações que envolvem proposição de ações de gestão das línguas e do multilinguismo, em contextos geopolíticos e em meio a situações sociolinguísticas várias, construídas com base em muitos enquadres políticos, sociais, culturais, epistemológicos. Nesse sentido, podemos afirmar que a Política Linguística não possui um quadro conceitual e terminológico fechado, mas que vem sendo tecido continuamente, nas relações sociais locais, regionais e globais, bem como em diferentes domínios: a família, as instituições de ensino, os espaços de culto, a paisagem urbana, as relações comerciais, as esferas legisladoras, dentre outros.

Conforme o título proposto, as linhas que se sucedem tematizam a pluralidade linguística e as políticas linguístico-educacionais. Ao estabelecer esse recorte, direcionamos o olhar para o domínio da escola e das formas de gestão do multilinguismo voltadas aos espaços de escolarização. Essa perspectiva parte do local de fala da pesquisadora como professoraformadora da área de Letras, em uma universidade situada em um ambiente 
sociolinguístico de fronteira, marcado pela pluralidade de línguas. São línguas que cresceram com esse território e outras que remontam a outros, criando diversas territorialidades nesse espaço de convívio e que, por isso, se trata de um espaço em que muitos indivíduos constroem seus repertórios linguísticos em meio a vivências plurais. Este texto retoma o pressuposto de que o multilinguismo e as línguas são objeto de gestão, visto que são moldadas, revitalizadas, apagadas ou invisibilizadas, como resultado de ação essencialmente humana e de múltiplos agentes. Segundo Oliveira (2020, p. 13), o termo gestão do multilinguismo

[...] aponta, por um lado, para a faceta interventiva das políticas linguísticas, com a incorporação do conjunto das vozes dos atores que, continuamente tomam decisões no campo linguístico e as implementam. Por outro lado, reconhece que nenhuma língua está sozinha, mas que integram conjuntos - repertórios - e que a gestão e o gestor incidem de modo complexo, hierárquico e específico sobre cada repertório.

Assim, no recorte adotado, compreendemos o domínio educacional como um espaço profícuo de investigação. Traçamos, como objetivo, estabelecer interlocuções em torno dos desafios e das potencialidades com que se depara a comunidade escolar em ambientes sociolinguísticos multilíngues no contraponto com o enquadre político-linguístico em que se inscrevem, centrando as discussões do texto na seguinte pergunta norteadora: quais os desafios e as potencialidades/possibilidades para a gestão com vistas à proposição de políticas linguísticas para o multilinguismo no Brasil?

No intuito de levar a cabo essa proposta, o texto está organizado em três partes. Primeiramente, são apresentadas as bases teóricas para se discutirem as políticas linguístico-educacionais e a gestão de línguas e do multilinguismo no domínio da escola. Em seguida, passamos a 
discutir os desafios e as potencialidades que se constituem como eixo dos questionamentos e das discussões em torno da promoção de políticas linguísticas para o multilinguismo, no Brasil. Na sequência, com o objetivo de promover outras interlocuções, são apresentadas breves ações desenvolvidas em uma instituição de ensino superior. Por último, nas considerações finais, apresentamos encaminhamentos para a continuidade das discussões e reflexões sobre a temática aqui exposta.

\section{Políticas linguístico-educacionais e gestão do multillinguismo no}

\section{domínio da escola}

Que línguas estão presentes nos currículos escolares? Quais delas são usadas como línguas de instrução dos conteúdos? O que (e em quais línguas) dizem os documentos norteadores acerca das práticas didáticopedagógicas e das leis que regulamentam as línguas a serem usadas, aprendidas e mantidas pelos alunos? Essas questões circundam o que podemos chamar de políticas linguístico-educacionais, ou seja, o conjunto de decisões sobre quais línguas (e variedades) devem estar presentes nos currículos e nas práticas pedagógicas, de que forma e quais "lugares" elas devem ocupar no domínio da escola, nas várias fases da vida escolar, ao longo do processo de escolarização.

Oliveira (2004, p. 38) define política linguística como “[...] o conjunto de decisões que um grupo de poder, sobretudo um Estado (mas também uma Igreja ou outros tipos de instituições menos totalizantes) toma sobre o lugar e a forma das línguas na sociedade, e a implementação destas decisões”. Tomando como norte essa definição mais ampla, podemos afirmar que, quando se trata de políticas linguístico-educacionais, referimo-nos, portanto, às decisões, ações, estratégias e práticas de gestão das línguas, desenvolvidas por governos (gestão in vitro) ou por agentes escolares, para os espaços de educação formal e também nesses espaços, intervindo 
nas relações das línguas com os sujeitos e incidindo sobre suas formas de aquisição/aprendizagem. Tal dinâmica ocorre em meio a condições sociais, políticas, econômicas e culturais que refletem ideologias linguísticas e que impactam na forma como os grupos sociais (re)agem frente às línguas e aos seus usuários.

Segundo Calvet (2007, p. 12), “[...] a política linguística é inseparável de sua aplicação", ou seja, o planejamento linguístico. Esse termo, que consolida o binômio política linguística-planejamento linguístico surge em 1959, em um trabalho de Einar Haugen (Planning in Modern Norway) que analisa, na Noruega, as intervenções do Estado sobre a situação linguística do país pós-independência. Para o linguista, o planejamento linguístico consiste em o Estado criar condições e recursos necessários para que as decisões sobre a resolução dos problemas linguísticos se concretizem (CALVET, 2007; SILVA, 2013).

Com a pujança do campo, diversos serão os modelos de planejamento linguístico propostos por linguistas em outros contextos, a partir da década seguinte. No entanto, de modo geral, essas ideias se centravam na resolução do que se convencionou classificar, pelos Estados, como problemas linguísticos de países em desenvolvimento, levando em conta o planejamento econômico e social da época, o que é corroborado por Berger (2015, p. 51), ao afirmar que “[...] prevalecia a ideia de língua enquanto meio de comunicação e a existência de variedades da língua (e do plurilinguismo) como um problema a ser contornado por ações no âmbito dos governos dos Estados". Assim, o planejamento linguístico operava como uma atividade com vistas a apagar diferenças e, de certo modo, em direção a formas de homogeneização linguística.

Ademais, dois enfoques de implementação das decisões sobre as línguas surgem, em um primeiro momento, na literatura, relativa ao campo: um que incide sobre peso das línguas e sobre suas funções (planejamento de status); e outro que recai sobre a forma das línguas (planejamento de 
corpus). Embora categorizadas separadamente, em verdade, elas se interrelacionam, de tal modo que, ao intervir nas formas das línguas, efeitos podem ser percebidos no peso que elas passam a ter na sociedade.

No que concerne à esfera educacional, o linguista Robert Cooper propôs em 1989 o que denominou de planejamento de aquisição de língua (language acquisition planning), tendo como argumento que a formulação de políticas linguísticas envolve decisões relacionadas com o seu ensino e uso, além de uma cuidadosa formulação dessas políticas. Para Cooper (1989), essa outra categoria de planejamento linguístico, para além do planejamento de corpus ou de status, justificar-se-ia porque grande parte dos esforços voltados à difusão de uma língua são empreendidos por meio da educação. Como consequência e aliada a outros fatores e estratégias, essa forma de planejamento poderia levar ao aumento do número de falantes de determinada(s) língua(s). Acrescentou, ainda, o fato de que a difusão de uma língua, na sociedade, conta, em grande medida, com as formas de gestão empreendidas no domínio educacional, espaço profícuo à implementação de políticas.

$\mathrm{Na}$ esteira dessa proposição, Kaplan e Baldauf (1997 apud MENKEN; GARCÍA, 2010) propuseram o que chamaram de language-ineducation planning, que traduzimos, aqui, como planejamento linguísticoeducacional. O termo relaciona-se com o que foi proposto por Cooper, mas tinha como fim não somente o aumento do número de falantes de uma ou de outra língua, mas seria, especificamente, uma forma de intervenção educacional sobre elas. Consideraram, portanto, que as políticas linguísticoeducacionais incidem sobre a seleção das línguas de instrução e sobre línguas-alvo do ensino, no âmbito da produção de recursos didáticos em determinadas línguas, da formação de professores de línguas, dentre outras formas de gestão inter-relacionadas.

Conforme proposto, essa forma de planejamento linguístico consiste em diferentes etapas que envolvem a proposição de uma política educacional 
e a articulação dessa política educacional a uma política curricular em que as línguas são descritas para serem implementadas pelo sistema de ensino; a formação dos recursos humanos para a implementação dessas políticas (professores e outros agentes); a criação de toda uma gama de recursos materiais necessários para fins dessa política (materiais didáticos, espaço instrucional, equipamentos, previsão de custos); o trabalho junto à comunidade escolar-alvo considerando as suas atitudes diante das línguas; e, por fim, uma cuidadosa avaliação da política implementada, no sentido de apreciar o currículo proposto, o resultado entre os alunos e professores, bem como a relação custo-benefício das políticas (MENKEN; GARCÍA, 2010).

Além dessas etapas, o planejamento envolve outras decisões como a escolha de quais línguas de instrução devem ser usadas para ministrar os conteúdos escolares; a definição dos lugares atribuídos a essas línguas nos currículos (língua materna, segunda língua, língua estrangeira, língua adicional, língua de herança, língua de acolhimento, etc.); a forma de distribuição da carga horária destinada para o ensino; a definição de modelos de ensino (mono/bi/multilíngue); as escolhas relacionadas às metodologias de ensino-aprendizagem; os requisitos para a formação dos professores; a gestão dos materiais instrucionais, dos critérios e formas de avaliação etc. Em síntese, todo esse conjunto constitui um modelo de gestão das políticas linguístico-educacionais, o que implica proposição, planejamento, implementação e avaliação.

Convém, ainda, acrescentar que a análise de políticas linguísticoeducacionais precisa reconhecer elementos que estão imbricados nessas decisões, a saber: as ideologias linguísticas, as políticas linguísticas explícitas e implícitas que compõem o enquadramento político-linguístico de gestão de línguas do país e quais são os agentes decisores dessas políticas, além de uma compreensão aprofundada do ambiente sociolinguístico e socioeducacional em que serão implementadas. 
Segundo Shohamy (2006), na maioria dos países com sistemas educacionais centralizados, as decisões em torno das políticas linguísticoeducacionais são tomadas por autoridades centrais ou locais. Conforme argumenta, em todas essas situações, elas servem como um mecanismo para implementar agendas das políticas linguísticas nacionais. Desse modo, são impostas de modo vertical (top-down policies) e, muitas vezes, implementadas, sem grande resistência, pela maioria das escolas. Para burocratas, caracterizam-se como uma grande oportunidade de exercer influência, pois reforçam várias ideologias sociais e políticas por meio das línguas.

Podemos mencionar, ainda, que a decisão por quais línguas estarão presentes nos currículos e no processo de escolarização, sob o estatuto de línguas de instrução ou de línguas-alvo da instrução, em geral, volta-se para línguas de maior prestígio e de reconhecido valor em determinada sociedade, a exemplo da(s) língua(s) oficial(s) do Estado e da(s) língua(s) às quais estão agregados valores econômicos e de trocas no âmbito internacional. É o caso do Brasil, em que, no português, coincidem os estatutos de língua oficial e de língua de instrução. Já as demais línguas são tratadas como línguas estrangeiras, na legislação educacional brasileira, à exceção de línguas indígenas e da Língua Brasileira de Sinais (Libras), para as quais há políticas linguísticas específicas.

À vista dessas considerações, podemos afirmar que a gestão das línguas e do multilinguismo, ou seja, da presença e do lugar de diversas línguas nos espaços de escolarização, caracteriza-se como um fenômeno complexo e multifacetado (SPOLSKY, 2009), que envolve diferentes relações de força que atuam sobre as línguas na sociedade e que não se encerra em instrumentos legais efetivados pelas comunidades escolares. Dito de outro modo, as decisões e intervenções estão intrinsecamente atreladas a ideologias linguísticas, a leis linguísticas e a orientações político- 
linguísticas (RUIZ, 1984)2 e, portanto, ao quadro político-linguístico de dada sociedade. Esse quadro diz respeito ao conjunto de práticas e saberes construídos em relação às línguas politicamente definidas e à pluralidade de línguas bem como às políticas linguísticas explícitas e implícitas vigentes, de modo que as formas de intervenção sobre as línguas presentes e ausentes, nos sistemas educacionais, são organizadas em torno desses conhecimentos e dos valores que são atribuídos a elas no tecido social, nos vários níveis do planejamento linguístico-educacional.

\section{Desafios e potencialidades para políticas linguístico-}

\section{educacionais rumo ao multillinguismo}

Para discorrer sobre os desafios e potencialidades existentes para a construção de políticas linguístico-educacionais que promovam a pluralidade linguística, faz-se necessário, inicialmente, abordar, ainda que brevemente, o quadro político-linguístico em que esse texto se situa. Ele evidencia a forma como o multilinguismo é (pode ser) compreendido, nos dias de hoje, levando em conta a história das ações sobre as línguas, no País, desde o período conhecido como Brasil Colônia.

Conforme abordado em estudos sobre políticas linguísticas no Brasil, embora o País tenha sido erigido em um território multilíngue, muitas línguas desapareceram (bem como seus falantes) em detrimento da língua portuguesa, primeiramente como língua da metrópole, depois como língua do Príncipe e, por fim, como língua nacional do Estado brasileiro. A sobreposição de valores de colonizadores europeus sobre a realidade sociolinguística do que viria a se tornar o País bem como ideais de uma

2 As orientações político-linguísticas referem-se a motivações em relação às línguas e aos papéis que desempenham na sociedade. Para Ruiz (1984), elas podem ser inconscientes ou não e residem em quaisquer argumentos em torno das línguas e seus papéis. O linguista classificou-as como: língua como problema (language as problem), língua como direito (language as right) e língua como recurso (language as resource). 
cultura nacional em que a coesão social era compreendida como unidade na uniformidade foram discursos que perpassaram e que se consolidaram na história linguística do Brasil.

Ações de repressão sobre línguas indígenas e de imigrantes que se estabeleceram no País, desde o primeiro quartel do século XIX, além do isolamento linguístico a que se submetiam negros escravizados vindo de África, são exemplos de formas determinantes de gestão das línguas para o apagamento e para a substituição de muitas línguas. Consoante Oliveira (2009, p. 20), “[...] [a] história lingüística do Brasil poderia ser contada pela seqüência de políticas lingüísticas homogeneizadoras e repressivas e pelos resultados que alcançaram".

Como efeito, discorrer sobre a pluralidade linguística, no domínio das escolas brasileiras, pressupõe relacioná-la com esse quadro que nos informa sobre as ideologias linguísticas circundantes, sobre o peso das línguas e do multilinguismo para essa sociedade, sobre as muitas políticas linguísticas implícitas e explícitas implementadas e sobre aqueles que exercem autoridade sobre os usos das línguas e tomam decisões sobre elas. Desse modo, podemos afirmar que as políticas linguístico-educacionais, no Brasil, foram orientadas conforme os discursos circundantes sobre as línguas e diante do efeito de conjunto das políticas linguísticas homogeneizadoras implementadas e implantadas no País, por séculos. Ademais, as políticas linguístico-educacionais explícitas (na forma de leis de línguas, de instrumentos normativos, de diretrizes etc.) devem ser encaradas como sendo, também, um mecanismo - termo empregado por Shohamy (2006) - que contribuiu para consolidar a ideia de nação monolíngue.

Diante desses pressupostos, o multilinguismo configura-se, hoje, como um desafio para as escolas brasileiras e instituições de ensino de modo geral, que foram organizadas em torno de uma política linguística historicamente construída, conferindo a centralidade para a língua 
portuguesa e a marginalidade e a invisibilidade de outras tantas línguas, precisamente daquelas que compõem cenários de bi e multilinguismo social (OLIVEIRA; ALTENHOFEN, 2011). É importante mencionar isso, porque, como é sabido, quando se trata de línguas ditas de prestígio e que representam ideais de modernização e de sucesso, o bilinguismo (de elite) é glorificado em muitos discursos e no senso comum.

Diante dessas constatações, é possível afirmar que há, no País, resquícios de uma orientação político-linguística (RUIZ, 1984) que lança uma perspectiva do multilinguismo como um "problema a ser resolvido", ou seja, o entendimento de que a pluralidade de línguas que desemboca na presença de falantes de outras línguas que não o português, nos espaços escolares, é, pois, um problema a ser sanado e contornado, com o qual as escolas precisam lidar, conduzindo processos de ensino-aprendizagem sem vozes que "perturbem" uma lógica de uniformidade e de homogeneidade linguística largamente instaurada.

Como exemplo dessa afirmação, referenciamos pesquisa realizada na fronteira Brasil-Paraguai, uma região intensamente multilíngue em que não somente coexistem línguas politicamente definidas como oficiais e nacionais (português, castelhano e guarani), como também muitas outras línguas de imigrantes e práticas linguísticas das mais plurais, que compõem um mosaico sociolinguístico da região (BERGER, 2015; 2020). No estudo conduzido em duas escolas brasileiras, onde há um expressivo contingente de alunos cujos repertórios multi e plurilíngues desafiam o enquadre político-linguístico monolíngue em que essas escolas se construíram, a autora identificou práticas escolares cotidianas de gestão do multilinguismo, a saber: interdição, vigilância, concessão e promoção simbólica, definindo-as como “[...] ações desenvolvidas no cenário escolar [...] em que se manifestam as relações de poder existentes nesse cenário e no entorno social, dentre as quais, as relações de poder entre as línguas e seus falantes." (BERGER, 2015, p. 162). 
Tais práticas, adotadas por educadores, diante de línguas que não a portuguesa, estavam alicerçadas em alguns fatores, a saber: atitudes linguísticas desfavoráveis diante do multilinguismo e de algumas línguas e seus falantes; preconceitos linguísticos sustentados em relações socioeconômicas desiguais e em relações de poder entre línguas, culturas e falantes; representação das fronteiras nacionais como "ponto de corte" entre o que pertence a uma nação e o que pertence à outra; representação das escolas brasileiras como "guardiãs" de uma pretensa cultura nacional e da língua nacional oficial. Além disso, foram identificados fatores como a falta de (ou o pouco) conhecimento e formação por parte de professores e educadores para lidar com realidades plurais, bem como um desconhecimento em relação à importância das línguas maternas dos alunos para seu desenvolvimento e aprendizagem.3 Estes últimos merecem destaque para a discussão proposta neste texto.

A formação precária ou inexistente de professores, em torno de questões relacionadas com as políticas linguísticas ou às potencialidades do plurilinguismo para o desenvolvimento de sociedades sustentáveis, é um dos tantos desafios com os quais urge lidarmos na agenda das políticas linguísticas para a promoção da pluralidade de línguas. Fraga (2014), em levantamento inicial da oferta de disciplinas que envolvessem políticas linguísticas em diversos cursos de graduação e pós-graduação do país, evidenciou que era ainda rara, na formação inicial, a discussão sobre as políticas linguísticas na forma de disciplinas que se dedicassem, sistematicamente, a esse assunto. Verificou que esses estudos se centravam, mormente, no âmbito da pós-graduação. Se fôssemos atualizar esses dados hoje, certamente, avanços nessa direção poderiam ser percebidos nos cursos de Letras, em face do crescente interesse por essa área do conhecimento e da robusta produção acadêmica sobre o tema que vem se consolidando no

3 Mais detalhes sobre esse estudo e seus resultados constam em BERGER (2015) e BERGER (2020). 
Brasil. Há, porém, ainda uma grande lacuna no que tange aos cursos de formação de professores para Educação Infantil e para os anos iniciais do Ensino Fundamental.

Na esteira dessa discussão, no que se refere a modelos de educação bi/multilíngue, o Brasil está, ainda, em uma jornada rumo a modelos de enriquecimento que valorizem o multilinguismo, que abandonem a perspectiva de que a pluralidade de línguas e a presença de sujeitos com repertórios plurais na escola se configura como um 'problema'. Várias pesquisas vêm evidenciando a necessidade dessa pauta na agenda de políticas linguístico-educacionais, no Brasil. E, nesse sentido, este texto inscreve-se em um momento histórico singular, em que as diretrizes para educação bi e plurilíngue estão sendo construídas como uma política linguística pública explícita do País. Em meio à pandemia de COVID-19,4 o Conselho Nacional de Educação (CNE) coloca em pauta uma antiga discussão sobre a necessidade de normatizar a educação bilíngue no País e lança, para consulta pública, minuta e resolução que dispõem sobre essa temática.

Até o momento, não existia uma política pública explícita para a criação de um modelo de ensino de línguas que se traduzisse no multilinguismo ou na consciência da importância da pluralidade linguística e do desenvolvimento de competências multilíngues. Apesar das contradições que são perceptíveis nessa política, precisamente, em termos de valores atribuídos às línguas, de problemas relacionados com a formação de professores para atuar em instituições bilíngues (conforme o que se pretende), mas também como abismo entre os sistemas privado e público de ensino, a política tem o mérito de voltar o olhar para a questão

4 Esta escrita se deu em meio à pandemia de COVID-19. O surto da doença respiratória impôs profundas mudanças nas relações sociais. Destacam-se a reconfiguração e a adaptação das instituições de ensino, que passaram a conduzir suas atividades remotamente. Foi o caso, por exemplo, das discussões em torno da minuta das diretrizes, conduzidas por meio de lives e de encontros remotos, que agregaram pessoas de todas as regiões do País. 
da educação linguística e, com isso, mobilizar professores de línguas e educadores, envolvendo-os em intensos debates virtuais, em meio à pandemia.

Assim, podemos sintetizar que a proposição e a gestão de políticas linguístico-educacionais para lidar com a presença de outras línguas nos espaços educacionais é um desafio a ser enfrentado, de modo que o multilinguismo deixe de ser encarado como um problema para a educação e possa ser repensado na perspectiva de suas potencialidades para a construção de saberes necessários à consolidação de sociedades plurais. Dito de outro modo, urge a compreensão de que, em sociedades do conhecimento, as muitas línguas constituem-se como um direito humano fundamental dos grupos que as falam e, no seu ápice, o entendimento de que o multilinguismo, ao veicular diversos saberes e ideias, constitui-se como um recurso para o desenvolvimento de sociedades mais democráticas e sustentáveis.

Diante disso, seguindo o objetivo aqui proposto, passamos, portanto, a ponderar sobre as potencialidades que se vêm instaurando para a construção de outro quadro, em que o plurilinguismo possa ser amplamente reconhecido como direito e recurso para desenvolvimento de sociedades linguisticamente e culturalmente sustentáveis.

Temos observado uma abertura de caminhos para a reflexão em torno da construção de novas políticas e práticas que atendam a variadas demandas linguísticas, culturais e educacionais e, com isso, um crescente interesse da sociedade, em geral, sobre a pluralidade de línguas. Citando Morello (2013):

Após atravessarmos um longo período de interdição de línguas em prol da construção de um Estado Nacional que reconheceu somente a língua portuguesa como língua oficial, vivemos, no presente, um momento inaugural de promoção da diversidade lin- 
guística $[\ldots]$.

Oliveira e Altenhofen (2011) apresentam um quadro das políticas linguísticas no Brasil desde a Constituição de 1988, em que podemos observar os primeiros movimentos do Estado brasileiro, em direção ao plurilinguismo. Um importante salto foi dado em relação aos direitos dos povos indígenas, frente às suas línguas e culturas. Na referida Lei Magna, a eles foi reconhecido e resguardado o direito de organizarem e de utilizarem seus processos de ensino-aprendizagem, em suas línguas maternas, de modo que "[...] a educação escolar indígena [foi] o grande laboratório que, pela primeira vez na história brasileira, gerou conhecimentos nesta área, tão avessa à construção da nação monolíngue e monocultural que foi a tônica das políticas educacionais no país." (OLIVEIRA; ALTENHOFEN, 2011, p. 203).

No que concerne às tantas outras línguas que contribuem para essa caracterização do Brasil como um país multilíngue, ações mais recentes seguem no fluxo desse movimento iniciado graças à demanda e da resistência das comunidades indígenas. Vivenciamos, também, a histórica regulamentação do uso de Libras, no ano de 2002, e de todas as políticas linguístico-educacionais que derivam desse primeiro e importante passo.

Além dessas, podem ser listadas, aqui, várias ações que se somam a esse movimento de reconhecimento e de valorização do potencial multilinguístico do Brasil. Citamos três deles: 1) a cooficialização de diversas línguas (indígenas e de imigração) em nível municipal; 2) o Seminário de Criação do Livro de Registro das Línguas, promovido pelo IPHAN, em 2006; 3) a criação do Inventário Nacional da Diversidade Linguística do Brasil em 2010. Derivam dessas políticas, por exemplo, o Inventário da Língua Guarani Mbya (MORELLO; SEIFFERT, 2011) e o Inventário da Língua Hunsrückisch (ALTENHOFEN; MORELLO, 2018). 
Em meio a esse panorama de políticas linguísticas internas, cabe também mencionar o Programa Escolas Interculturais de Fronteira, instituído em 2012, com o objetivo de promover a integração regional por meio da educação intercultural e bilíngue. Embora, em termos de planejamento, essa política não tenha ainda conseguido alcançar sua potencialidade (SAGAZ, 2013), representa um marco para pensar a gestão das línguas, em regiões marcadas por grande complexidade linguística e cultural, como o são as fronteiras. Podemos afirmar, nesse sentido, que, no que concerne às políticas linguísticas para as regiões de fronteira, precisamente com vistas à valorização do potencial multilíngue e multicultural dessas regiões, do ponto de vista educacional, é recente o trilhar desse caminho.

Diante dessa configuração que se instaura paulatinamente no País, podemos concluir que as intensificadas discussões sobre as políticas linguísticas para o multilinguismo vêm consolidando um espaço para a construção de novas atitudes e representações diante da pluralidade de línguas. Isso pode ser constatado pela intensa mobilização de comunidades, de educadores, de pesquisadores e de professores de línguas em diferentes frentes que demandam a valorização de diferentes línguas que compõem a pluralidade do País bem como a visibilização de comunidades linguísticas, há tempos postas à margem, quando se trata de suas línguas, de suas culturas e de suas memórias. Podemos destacar, a título de exemplo, movimentos como \#FicaEspanhol, em resistência a políticas de homogeneização linguística às avessas, em favor da língua inglesa, nos currículo escolares; a prontidão e a resistência da comunidade surda na luta pelos seus direitos de uso e por uma gestão adequada que contemple, devidamente, as demandas socioeducacionais; bem como a intensa mobilização e reação de professores de todo o território nacional diante das minutas das Diretrizes Curriculares Nacionais (DCN) para a oferta de educação (bi)plurilíngue, no ano de 2020. 
Hoje, portanto, depois de um longo período de invisibilização de línguas e de práticas linguísticas no País, como efeito de políticas linguísticas homogeneizadoras e excludentes, já é possível perceber que modelos educacionais centrados no ensino de/em uma língua nacional única não são suficientes para lidar com um número de situações sociolinguísticas nas quais a diversidade é imperativa, como aldeamentos indígenas, contextos de fronteira, de línguas de imigração, entre outros, onde há inúmeros imigrantes, descendentes ou refugiados, advindos de outros países, em busca de melhores condições de vida.

Essas reflexões partem da premissa de que a política linguística opera em diferentes níveis e esferas de gestão in vitro (CALVET, 2007), como também em políticas locais. Pressupomos que é necessária a proposição de políticas linguísticas explícitas que regulamentem e orientem formas diversas de planejamento de programas de educação (intercultural) bilíngue no País e que, desse modo, em cada contexto, agentes locais e membros da comunidade escolar possam atuar em formas de inserção, de valorização e de promoção de línguas e de culturas diferentes, na esfera escolar.

Acrescenta-se, por fim, a assunção de que a proposição e a oficialização de tais políticas levariam ao compromisso das esferas administrativas públicas de atuar, também, no planejamento necessário à regulamentação e à implementação de modelos de educação bi, multi e plurilíngue, promovendo a captação e o direcionamento de recursos para o desenvolvimento de tais ações, com vistas à garantia de direitos linguísticos e de condições de cidadania plena.

Diante desta exposição, podemos afirmar que há um número de experiências válidas desenvolvidas, em diferentes contextos geopolíticos e em ambientes sociolinguísticos, que podem trazer luz e servir de eixo para reflexão sobre essa pauta, como ensino de línguas de acolhimento, tipos de educação bilíngue de enriquecimento, pedagogia da translinguagem, ensino-aprendizagem de línguas baseados na intercompreensão, 
pedagogias interculturais.

Para além dessas experiências, medidas e ações de enfrentamento que desafiem essa lógica monolíngue e esse valor que se atribui somente línguas de prestígio devem estar relacionadas com a consistente formação inicial, principalmente de professores da área de Letras e de Estudos da Linguagem, em que seja contemplado necessariamente, o estudo das políticas linguísticas. Isso para que formemos profissionais que percebam a configuração dos muitos ambientes linguísticos pelo viés político e para que não perpetuem preconceitos em suas práticas, compreendendo as relações de poder que alicerçam as muitas facetas da gestão das línguas.

Nesse sentido, mencionamos, como exemplo, algumas das iniciativas implementadas no âmbito da universidade em que a pesquisadora se insere, desenvolvidas em torno da temática aqui apresentada: a) realização de projetos de ensino, de extensão e eventos voltados à comunidade em geral em torno do fenômeno do multilinguismo, com o objetivo de promover a sensibilização e valorização quanto à riqueza linguística e cultural da região; b) desenvolvimento de atividades de formação continuada para professores de modo a prover insumos teóricos e debates para que possam refletir sobre o direito ao uso das línguas maternas nos processos de escolarização; c) adaptação da grade curricular do Curso de Letras que passou a ofertar, desde o ano de 2017, uma disciplina cujo objetivo é abordar o panorama sociolinguístico brasileiro, discutir as políticas linguísticas e sua relação com o ensino-aprendizagem em contexto de pluralidade linguística, e, por fim, d) adesão da universidade a uma rede de pesquisa especializada em políticas linguísticas para o multilinguismo, fomentando investigações e a construção de saberes em torno da pluralidade de línguas e de práticas que derivam desse fenômeno, nos âmbitos público e privado.

Partindo da perspectiva de que educadores são sujeitos capazes de desempenhar um papel importante e ativo na gestão das políticas linguísticas e do multilinguismo (MENKEN; GARCÍA, 2010; JOHNSON, 
2013), outra iniciativa possível seria a realização de investigações, com base na abordagem metodológica da pesquisa-ação, propiciando aos educadores a oportunidade de questionarem a forma como interpretam, (re)criam e se apropriam das políticas linguístico-educacionais, em face de múltiplos repertórios linguísticos e culturais de estudantes e comunidade.

Tais investigações podem envolver desde mapeamentos linguísticos e diagnósticos, para depreender atitudes linguísticas da comunidade escolar, à proposição e implementação de práticas pedagógicas visando à conscientização quanto à riqueza linguístico-cultural da escola e do entorno e suas demandas bem como a proposição de ações para valorização e promoção do multilinguismo nas práticas cotidianas do domínio da escola. Em resumo: "Ao trabalharem colaborativamente, equipes de pesquisadores e educadores que entendem o contexto local e o enquadre maior da pesquisa são capazes de trabalhar juntos para promover espaços ideológicos locais que promovam políticas linguísticas multilíngues'. (JOHNSON, 2013, p. 213-214, tradução nossa).

Passamos, portanto, às palavras finais.

\section{Considerações finais}

Este texto teve como objetivo estabelecer interlocuções quanto aos fatores que incidem na gestão do multilinguismo, visando à promoção da pluralidade das línguas no Brasil, bem como discutir sobre quais os desafios e as potencialidades/possibilidades para a gestão com vistas à proposição de políticas linguísticas para o multilinguismo no País.

Como resultado da discussão apresentada, para finalizar, propomos, na sequência, quatro encaminhamentos com vistas a manter, localmente, a reflexão, a pesquisa e o debate em torno da proposição e da ação em direção a políticas linguístico-educacionais que possam, efetivamente, confrontar positivamente a diversidade linguístico-cultural que se põe nos 
espaços educativos:

a) Identificar, sistematicamente, o perfil sociolinguístico da comunidade escolar, por meio de diagnósticos linguísticos e de práticas pedagógicas, para compreender e refletir sobre o ambiente sociolinguístico do entorno e as relações dos diversos sujeitos com as línguas;

b) Refletir sobre o modo como a presença de diferentes línguas no espaço escolar são percebidas e geridas pela comunidade escolar (pais, alunos, professores etc.), visando identificar se são consideradas como problemas, como direitos ou como potenciais recursos da comunidade;

c) Realizar discussões e promover reflexões sobre o quadro políticolinguístico-educacional que norteia as diversas ações sobre as línguas na/ da instituição educacional, no sentido de engajamento de educadores para a proposição de mudanças e de novas direções (debate $\rightarrow$ pesquisa $\rightarrow$ formação continuada);

d) Investigar e refletir sobre diferentes abordagens e modelos de gestão de línguas na educação formal, a fim de se construir caminhos e propor decisões informadas em teoria e prática.

Dado o exposto, encerramos este texto enfatizando que, quando nos referimos a políticas de gestão para a promoção do multilinguismo, não se trata somente de línguas, mas de ações que promovam o respeito às mais variadas formas de diversidade, às mais variadas culturas e visões de mundo e às memórias e histórias que coletividades e indivíduos constroem em suas tantas línguas e em meio a contextos multi e plurilíngues.

\section{Referências}

ALTENHOFEN, Cléo Vilson; MORELLO, Rosângela (org.). Hunsrückisch: Inventário de uma língua do Brasil. Florianópolis: Garapuvu, 2018. 
BERGER, Isis Ribeiro. Gestão do multi/plurilinguismo em escolas brasileiras na fronteira Brasil-Paraguai: um olhar a partir do Observatório da Educação na Fronteira. 2015, 298p. Tese (Doutorado em Linguística) - Programa de Pós-graduação em Linguística, Universidade Federal de Santa Catarina, Florianópolis, Santa Catarina, 2015.

. The role of attitudes in the management of multilingualism in Brazilian schools located in the Brazil-Paraguai border region. In: BUGEL, Talia; MONTES-ALCALÁ, Cecilia. New approaches to Language Attitudes in the Hispanic and Lusophone world. Amsterdam: John Benjamins Publishing Company, 2020. p. 83-107.

CALVET, Louis-Jean. As políticas linguísticas. São Paulo: Parábola Editorial; Florianópolis: IPOL, 2007.

COOPER, Robert Leon. Language planning and social change. New York: Cambridge University Press, 1989.

FRAGA, Letícia. Políticas linguísticas na formação do licenciado em Letras: uma discussão introdutória. In: CORREA, Djane Antonucci. Política Linguística e ensino de língua. Campinas: Pontes Editores, 2014. p. 45-58.

JOHNSON, David Cassels. C. Educational language policy engagement and action research (ELPEAR). In: JOHNSON, David Cassels. Language policy. Research and Practice in Applied Linguistics. London: Palgrave Macmillan, 2013. p.170-214

MENKEN, Kate; GARCÍA, Ofelia. Negotiating Language Policies in Schools: educators as policymakers. New York: Routledge, 2010.

MORELLO, Rosângela. A Carta de Maputo e as Políticas Linguísticas no 
Brasil. In: INSTITUTO DE INVESTIGAÇÃO E DESENVOLVIMENTO EM POLÍTICA LINGUÍSTICA (IPOL). Políticas Linguísticas no Brasil: o reconhecimento das línguas brasileiras e as demandas por ações articuladas e inovadoras. Florianópolis: IPOL, 2013. Disponível em: < https://bit. ly/30Xvuxa.> Acesso em: 12 out. 2020.

MORELLO, Rosângela; SEIFFERT, Ana Paula (org.). Inventário da Língua Guarani Mbya. Inventário Nacional da Diversidade Linguística. Florianópolis: IPOL, Garapuvu, 2011.

OLIVEIRA, Gilvan Müller de. Plurilinguismo no Brasil: repressão e resistência linguística. Synergies Brésil, [s.l.], v. 7, p. 19-26, 2009. Disponível em: < https://gerflint.fr/Base/Bresil7/gilvan.pdf $>$ Acesso em: 24 fev. 2015.

- Política Linguística, Política Historiográfica: epistemologia e escrita da história da(s) língua(s) a propósito da Língua Portuguesa no Brasil Meridional (1754 - 1830). 2004, 222f. Tese (Doutorado em Linguística) - Programa de Pós-Graduação em Linguística, Universidade Estadual de Campinas, Campinas, São Paulo, 2004.

. Prefácio: A gestão do multilinguismo na ótica do glocal. In: BERGER, Isis Ribeiro; REDEL, Elisângela. (org.). Políticas de gestão do multilinguismo: práticas e debates. Campinas: Pontes Editores, 2020.

.; ALTENHOFEN, Cleo. O in vitro e o in vivo na política da diversidade linguística no Brasil: inserção e exclusão do plurilinguismo na educação e na sociedade. In: MELLO, Heliana; ALTENHOFEN, Cléo; RASO, Tommaso (org.). Os contatos linguísticos no Brasil. Belo Horizonte: Editora da UFMG, 2011. p.187-216.

ORLANDI, Eni. Política linguística no Brasil. São Paulo: Pontes Editores, 
2007.

RUIZ, Richard. Orientations in language planning. NABE Journal, London, v. 8, n. 2, p. 15-34, 1984.

SAGAZ, Márcia Regina Pereira. Projeto Escolas (Interculturais) Bilíngues de Fronteira: análise de uma ação político linguística. 2013. Dissertação (Mestrado em Linguística) - Programa de Pós-Graduação em Linguística, Universidade Federal de Santa Catarina, Florianópolis, 2013. 156 f.

SAVEDRA, Mônica Maria Guimarães; LAGARES, Xoán Carlos. Política e planificação linguística: conceitos, terminologias e intervenções no Brasil. Gragoatá, Niterói, v. 17, n. 32, n. 32, p. 11-27, $1^{\text { }}$ sem. 2012.

SHOHAMY, Elana. Language Policy: hidden agendas and new approaches. New York: Routledge, 2006.

SPOLSKY, Bernard. Language management. UK: Cambridge University Press, 2009.

SILVA, Elias Ribeiro da. A pesquisa em Política Linguística: histórico, desenvolvimento e pressupostos epistemológicos. Trabalhos em Linguística Aplicada, Campinas, v. 52, n. 2, p. 289-320, jul./dez. 2013.

Linguistic plurality and language in education policies in Brazil: towards multilingualism management

Abstract: This article addresses the linguistic plurality and language in education policies in Brazil and discusses the forms of multilingualism management in education. The text, whose objective is to establish dialogues regarding the factors that affect the management of multilingualism aiming at the promotion of the plurality of languages in the country, starts from the assumption that multilingualism and languages are the object of management, in which power relations and actions of multiple agents are observable. For 
this purpose, the theoretical framework on which the discussions are based is initially presented: language policies, language in education policies, language and multilingualism management at school. Then we discuss the challenges and potentialities that constitute the axis of the debates around the promotion of linguistic policies for multilingualism in Brazil. Finally, we present experiences and actions that challenge the monolingual political-linguistic framework that has been built in the country for a long time, and also, guidelines are presented for the continuation of discussions and reflections on the theme presented here.

Keywords: Language in education policies. Management. Multilingualism. Brazil.

Recebido em: 13/11/2020

Aceito em: 24/04/2021 